\title{
BEYOND ACCESS AND BARRIERS: INCLUSIVE EDUCATION AND SYSTEMS CHANGE
}

\author{
Matthew J. Schuelka ${ }^{1}$ \\ University of Birmingham, United Kingdom
}

\author{
Alisha M. B. Braun \\ University of South Florida, USA \\ Christopher J. Johnstone \\ University of Minnesota, USA
}

\section{Introduction}

Inclusive education is understood in a variety of ways. In fact, a lot of scholarly energy has been put into defining and re-defining 'inclusive education' over the past two decades and shows little sign of abating. In this introduction to the special issue, we prefer to give a brief overview of the global discourse on inclusive education without getting pulled too deeply into murky ontological and semantic waters. In essence, we believe that endless debates over the definition of 'inclusive education' serves much less practical purpose than might be supposed. To keep it simple and pragmatic, we prefer the conceptualization of inclusion and diversity in education' (Schuelka, Johnstone, Thomas \& Artiles, 2019) in which the end goals of inclusivity are assumed within the definition of 'education' itself. This is a distinctly contemporary position that seeks to forge a new path away from 'special' or segregated education, and calls for a radical re-thinking of educational values, outcomes, and processes.

Historically, education was - and in many ways still is - a homogenous exercise for the elite few. Universal education discourses have only been present within the past hundred years or so, and global access to quality education remains a challenge. Despite this, in the 21 st century, we are in an era where educational participation is viewed nearly as a right for every citizen in every country - even if in practice this is not always the case. Moving from an elite education system to an education system supposedly for everyone has not been, and is not, an easy process.

At its core, there is a tension within education systems around the world between the dual purposes of education in the form of public collective good versus private individual good (Labaree, 1997). Inclusivity in education certainly plays into this tension, and exhibits it itself, in terms of the participation of groups of students traditionally marginalized in education. Group attributes and individual identities such as gender, race, ethnicity, economic status, and 'disability' have all necessitated specific policy and legislation to enable educational access and participation. Within global discourse, this has often occurred within the human rights

${ }^{1}$ Correspondence: School of Education, University of Birmingham, Edgbaston B15 2TT, United Kingdom; Email: m.schuelka@bham.ac.uk 
framework and followed a progression of declaration and initiatives in the United Nations such as the Jomtien Educational for All declaration in 1990, the 1994 Salamanca Statement, the Millennium Development Goals, the 2006 Convention on the Rights of Persons with Disabilities, and now to 2015-2030 Sustainable Development Goals. A similar progression of educational rights of marginalized populations can be seen in many countries. For example, in the United States with legal action from the Brown v. Board of Education decision in 1954, to the 1965 Elementary and Secondary Education Act, to the 1990 reauthorized Individuals with Disabilities Education Act.

However tempting it may be to view initiatives above as a relentless progressive march of inclusivity in education, in reality it is not so direct. The tension between public good versus private good is also found in the guise of the dilemmas of difference (Minow, 1990), whereby people enjoying specialized rights to address marginalization are coupled with ascriptions of 'abnormality' in a system that presumably functions for everyone. In terms of inclusion in education, the dilemma resides primarily in the balance of identity, representation, individuality, and 'sameness'. It has been effectively argued that contemporary notions of 'inclusive education' are very much a product of the previous segregated special education system (Richardson \& Powell, 2011). Many would continue to argue that 'inclusive education' remains in the shadow of 'special education' (Armstrong, Armstrong \& Spandagou, 2010; Slee 2011). In many countries, such as the United Kingdom, there has marked backlash against 'inclusive education' -- even a reassessment of its original arguments and premises by those that were instrumental in its inception (Warnock, 2005). In a recent book, Imray and Colley (2017) boldly declared Inclusion is dead: Long live inclusion, to which many scholars are now pitching tents on either side of the argument. (For a direct critical response, see Slee, 2018.) For us, these trends are indicative of the need of inclusion in education to further break away from its 'special' past and into promising and bolder new grounds.

Much scholarly attention has been placed in the last few decades on the structural and existing barriers toward access and participation in education for students from historically marginalized groups. This was important work, particularly in shining a light on the builtin homogenous structural assumptions of education. We argue that we have now reached a place in inclusive education scholarship where new lines of research are needed to complement the extensive examination of barriers to education. In some ways, a perseveration on educational barriers has led to a significant 'deficit-mindset' that is counterproductive to inclusivity, diversity, and pluralism in education. Given the growing discourse on the 'limits to inclusion', we propose that scholarship on inclusion in education become more systems oriented and more socio-culturally embedded.

Inclusive education discourse often turns to the examination of classroom barriers and access strategies, and generally assumed only as strategies for students with disabilities. Research in these areas is still relevant to the field because decades of research on barriers still has not produced an end to such barriers. However, the concept (or construct) of 'inclusion' is also in need of analysis, both in relation to and beyond barriers for students with disabilities. As noted above, scores of theoretical papers have attempted to define what 
inclusive education is. Discursive arguments may linger, but this special issue represents an opportunity to shift inclusive research in a different direction. In this issue, authors from around the world have avoided the theoretical trap of describing an imagined inclusion and have provided empirical accounts of 'what's going on' in the field. We are excited for the contribution that this issue will make to the field because of its diversity of authors, settings, and inclusion experiences. Rather than debate whether or not inclusion should exist - and for which populations - authors start at an elevated space of acknowledgement that inclusive education already is in practice, and that rigorous, critical research is needed in order to shape practice, dispel rumors, adequately characterize its magnitude (and for whom), inform theory, and rethink theory. In the pages that follow, articles move beyond debates about whether or not inclusive education is a good idea. Rather, the articles acknowledge its global presence and then begin to address how it exists, in what specific contexts it is implemented, and why individual studies can contribute to a broader, contemporary knowledge base than has been previously considered.

The theme of this Special Issue of the Forum for International Research in Education is "Beyond Access and Barriers: Inclusive Education and Systems Change." Its aim is to broaden our understandings of inclusive education, within broader themes of comparative and international education by focusing on policy-level understandings, school-society relationships, experiences of belonging and inclusion, and inclusive outcomes. This special issue explores how educational systems can respond to students disadvantaged in a variety of ways - either within schools and school cultures themselves; or by external factors, individual, or group characteristics. Articles in this edition focus on the broad-based impact of inclusion as an agent of change for education systems around the world. Echoing the global reach of the inclusive education movement, multiple world regions are represented in the articles herein, including North America (USA), South and Central America (Ecuador and Honduras), the Middle East (Jordan), and Europe (France, England, and others).

Extending our macro to micro policy-level understanding of the connections between policy and practice, some of the articles are focused on international, regional, and national inclusive education policy reform. Situated primarily at the first two levels, Ramberg and Watkins describe current developments concerning inclusive policy and practice in Europe. Reflecting on their cross-cultural quantitative analysis of special educational needs identification data, the authors highlight the challenges of investigating barriers to educational change at international and European levels for comparative researchers and policymakers to consider. Moving to increasingly micro levels of policy analysis and shifting geographically to the Middle East, Benson outlines the current state of inclusive education at international, national, and local levels in Jordan. Applying a modified comparative case study framework building from Schuelka (2018a) and Bartlett and Vavrus (2017), Benson provides unique insights about Jordan's adoption of inclusive policy, bringing attention to the influence of global forces and the resultant negotiation that occurs during local policy implementation. Jointly, these two articles serve to problematize the seemingly elusive progressive march of inclusive education discussed above by illustrating the intricacies that 
are involved when attempting to translate and apply shifts in international inclusive education policy discourse to regional, national, and local contexts.

Several of the articles in this special issue focus on the complexities and experiences in belonging and inclusion much closer to the micro-level, with an emphasis on the voices of participants themselves. Bittencourt, in his ethnographic work in Ecuador, explores the unintended consequences of a supposedly inclusive education policy change. It astutely explores the complexity and lived-experience of persons in schools in relation to system changes. Bittencourt also demonstrates the power of ethnography as a methodological tool in understanding the experiences of inclusion. Welply advances a sophisticated and theoretically rigorous take on the systemic dilemmas in inclusion and diversity in education. Her article explores the identity narratives of children from immigrant backgrounds in primary schools in France and England, with contrasting policy approaches towards 'inclusion' in each country that has consequences to the experiences of belonging for youth.

The two articles summarized above all touch upon an important and emerging trend in inclusive education scholarship: understanding and highlighting the lived-experience of participants and stakeholders. All too often, research on inclusion in education focuses too much attention on inputs and outputs, or the inclusive attitudes of certain groups over others. None of this kind of research speaks to the daily realities within schools themselves. More recent scholarship is pushing inclusive education research in directions such as a focus on psychological belonging (Braun, 2019), the depth of inclusive experience (Engsig, 2019), the socio-cultural production of disability in schools (Schuelka, 2018b), and youth resistance to produced disabled identities (Baines, 2014), to name just a few.

At the same time, any broad-based initiative needs to demonstrate some outcomes in order to gain political support. Inclusive education represents an opportunity for scholars to rethink traditional indicators of education that fail to recognize processual experiences of students (see Baines, 2014; Braun, 2019; and Engsig, 2019). Research that both examines relevant indicators of inclusive education and draws conclusions about its outcomes is valuable for educators and policymakers. The value of outcomes-based studies is the knowledge that allows local stakeholders to adapt, replicate, or re-envision models that are deemed successful through the examination of particular outcomes indicators.

Two studies in this issue provide such outcomes data. Ketner, for example, reports on the importance of teacher knowledge in inclusive education. Ketner's work extends conversations about the rights of children with disabilities to attend 'regular' schools in Honduras by providing data on teacher development outcomes. Similar to studies in other parts of the world (Johnstone \& Chapman, 2009), Ketner's findings reveal that the inclusion of a new population of children in schools (in this case, children with disabilities) requires teachers' toolkits and skill-bases to expand. The study provides empirical data that moves from a rhetorical focus on the importance of inclusion to a pragmatic description of the ways that inclusion advocates can support teachers to be effective in newly-inclusive schools.

Finally, Choi, McCart, and Sailor link school-wide supports with the educational outcomes of students with disabilities. In a multi-year study, the authors find that students who learn in schools with comprehensive, multi-tiered systems of supports (academic and 
behavioral) were more likely to reach proficiency on standardized assessments than those who do not. This study provides important data for the field of inclusive education for two reasons. First, there are inherent assumptions in schools that some students can, and some students cannot, succeed academically because of particular disability or other demographic labels. Choi et al. demonstrate that achievement is not static in any student if appropriate supports are provided. Their research does not promise that all students will achieve the same, but does demonstrate that academic growth is feasible for all students. Second, Choi et al.'s work demonstrates the importance of whole school reform. McMaster (2015) frames inclusive education as the responsibility of every single person in a school. Choi et al. build on these principles by demonstrating the ways school leaders, support staff, teachers, and parents can work together to provide targeted assistance to students who need extra support, while at the same time creating an overall culture of shared expectations in schools.

Together, these articles represent innovative and bold new steps in global inclusive education research. They move beyond the outdated debate on whether inclusivity 'works' and in trying to generate evidence to support its practice. Rather, the authors in this issue represent a trend in inclusive educational research that focuses on process, participant experience, outcomes, quality, and locating existing 'inclusivities' in education around the world. Many of the articles delve into sophisticated analytical layers, sites, and levels, which is entirely appropriate given similar trends in comparative and international education (Schuelka \& Lapham, 2019). An instrumentalist reification of inclusive education policies and definitions, and a deficit 'barriers and challenges to inclusion' mindset, is no longer convincing research that can be applied in practice. Ultimately, we argue that it is the experience and process of inclusion and diversity in education across layers, sites, and levels that warrants our research attention and imagination now and in the future.

\section{REFERENCES}

Armstrong, C.A., Armstrong, D. \& Spandagou, I. (2010). Inclusive education: International policy and practice. London: SAGE.

Baines, A.D. (2014). (Un)learning disability: Recognizing and changing restrictive views of student ability. New York: Teacher's College Press.

Bartlett, L. \& Vavrus, F. (2017). Rethinking case study research: A comparative approach. New York: Routledge.

Braun, A.M.B. (2019). Psychological inclusion: Considering students' feelings of belongingness and the benefits for academic achievement. In M.J. Schuelka, C.J. Johnstone, G. Thomas \& A.J. Artiles (Eds.), The SAGE handbook on inclusive and diversity in education (pp. 66-75). London: SAGE.

Engsig, T.T. (2019). The experience of inclusion in Danish schools: Between politicization and pedagogical ideals. In M.J. Schuelka, C.J. Johnstone, G. Thomas \& A.J. Artiles (Eds.), The SAGE handbook on inclusive and diversity in education (pp. 380-391). London: SAGE.

Imray, P. and Colley, A. (2017). Inclusion is dead: Long live inclusion. London: Routledge. 
Johnstone, C.J. \& Chapman, D.W. (2009). Contributions and constraints to inclusive education policy implementation in Lesotho. International Journal of Disability, Development, and Education, 56(2), 131-148.

Labaree, D.F. (1997). Public goods, private goods: The American struggle over educational goals. American Educational Research Journal, 34(1), 39-81.

McMaster, C. (2015). Educating All: Developing inclusive cultures from within. New York: Peter Lang.

Minow, M. (1990). Making all the difference: Inclusion, exclusion, and American law. Cornell, NY: Cornell University Press.

Richardson, J.G., \& Powell, J.J.W. (2011). Comparing special education: Origins to Contemporary paradoxes. Stanford, CA: Stanford University Press.

Schuelka, M.J. (2018a). Advancing a comparative case study approach towards education and disability research: An example from Bhutan. In N. Singal, P. Lynch, and S. Johansson (Eds.), Education and disability in the global south: New perspectives from Asia and Africa (pp. 89-106). London: Bloomsbury.

Schuelka, M.J. (2018b). The cultural production of the "disabled" person: Constructing difference in Bhutanese schools. Anthropology and Education Quarterly, 49(2), 183-200.

Schuelka, M.J., Johnstone, C.J., Thomas, G. \& Artiles, A.J. (Eds.) (2019). The SAGE handbook on inclusion and diversity in education. London: SAGE.

Schuelka, M.J. \& Lapham, K. (2019). Comparative and international inclusive education: Trends, dilemmas, and future directions. In A.W. Wiseman (Ed.), Annual review of comparative and international education 2018 (pp. 35-42). International Perspectives on Education and Society, Vol. 37. Bingley, UK: Emerald.

Slee, R. (2011). The irregular school: Exclusion, schooling, and inclusive education. London: Routledge.

Slee, R. (2018) Inclusive education isn't dead: it just smells funny. London: Routledge.

Warnock, M. (2005). Special educational needs: A new look. London: Philosophy of Education Society of Great Britain Publications.

\section{About the Authors}

Matthew J. Schuelka, PhD, is Lecturer of Inclusive Education at the University of Birmingham. His primary area of scholarship concerns sociocultural understandings of disability and education, and a focus on design and systems of schooling for all students. He holds advanced degrees from the University of Vermont, Stanford University, and the University of Minnesota ( $\mathrm{PhD}$ in Comparative International Education and Development). Dr. Schuelka has been involved in education, research and development projects all over the world, including Zambia, Malaysia, India, the United States, the United Kingdom and particularly in the Himalayan country of Bhutan. At the time of this writing he is Principal Investigator on two major research projects in Bhutan: a Toyota Foundation project on educational values on Bhutanese education and a UK Global Challenges Research Fund project on social participation and inclusive employment for Bhutanese youth with 
disabilities. Dr. Schuelka is the editor of the recent volumes Education in Bhutan: Culture, Schooling, and Gross National Happiness and The SAGE Handbook on Inclusion and Diversity in Education.

Alisha M. B. Braun, PhD, is an Assistant Professor of Social Foundations in the Department of Educational and Psychological Studies at the University of South Florida. Her research interests include educational policies related to access to quality education for marginalized children, especially disadvantaged children in developing contexts. Her current research focuses on inclusive education policy for students with disabilities in sub-Saharan Africa. Dr. Braun completed her PhD in Educational Policy from Michigan State University with graduate specializations in International Development and African Studies. She has a background in psychology with an M.A. in School Psychology from Michigan State University and a B.A. in Psychology from the University of Calgary.

Christopher J. Johnstone, $\mathrm{PhD}$, is an Assistant Professor of Comparative and International Development Education at the University of Minnesota. His research examines how educational systems become more responsive to the diversity of stakeholders they serve through the conscious removal of barriers and the development of enabling environments. Dr. Johnstone coordinates his university's Leadership in International and Intercultural Education PhD program and has worked professionally in over forty countries. He has worked extensively with organizations such as UNICEF, the US Department of State, and others on inclusive education and inclusive youth development projects. At the time of this writing, he currently serves as the co-lead for Kenya in the 'Learn, Earn, Save' project, the Principal Investigator of a Global Spotlight Grant study of disability identity in India and the Principal Investigator for a six-university case study on accessibility in learning abroad, as well as working on two US Department of State grants focused on inclusive education (with partners in Armenia, India, Kazakhstan and Ukraine). His recent work can be found in Prospects, International Journal of Education and Development and the British Journal of Educational Technology. 